\title{
Produtividade e Valor Nutritivo do Capim-Elefante cv. Napier sob Doses Crescentes de Nitrogênio e Potássio 1
}

\author{
Alex Carvalho Andrade ${ }^{2}$, Dilermando Miranda da Fonseca ${ }^{3}$, José Alberto Gomide ${ }^{4}$, \\ Victor Hugo Alvarez V. ${ }^{5}$, Carlos Eugênio Martins ${ }^{6}$, Daniel Pacífico Homem de Souza ${ }^{7}$
}

RESUMO - Avaliaram-se os efeitos das adubações nitrogenada e potássica sobre o capim-elefante “Napier”. Quatorze combinações entre $\mathrm{N}$ e K, de um fatorial incompleto de $\mathrm{N}$ e K, avaliados em sete doses de N (20, 50, 100, 200, 300, 350 e $380 \mathrm{~kg} / \mathrm{ha}$ de $\mathrm{N})$ e sete de $\mathrm{K}(16,40,80,160,240,280$ e $304 \mathrm{~kg} / \mathrm{ha}$ de K), foram obtidas de acordo com a matriz Box Berard aumentada 3, com acréscimo de um ponto. Os tratamentos foram distribuídos em blocos ao acaso com três repetições. A produtividade foi aumentada pelas adubações nitrogenada e potássica em $86 \%$. A relação lâmina/colmo e o teor de $\mathrm{Mg}^{2+}$ diminuíram com a adubação potássica. Os teores de $\mathrm{Pe} \mathrm{Ca}^{2+}$ diminuíram com a adubação nitrogenada, enquanto o teor de proteína bruta aumentou de maneira quadrática pelas adubações nitrogenada e potássica. O teor de $\mathrm{K}$ aumentou com a adubação potássica e diminuiu com a nitrogenada. O nível crítico de potássio na planta foi $1,85 \mathrm{dag} / \mathrm{kg}$ na matéria seca.

Palavras-chave: matéria seca, minerais, nível crítico, proteína bruta

\section{Elephant grass Napier cv. Mass Production and Nutritive Value under Increasing Levels of Nitrogen and Potassium Fertilizers}

\begin{abstract}
The effects of nitrogen and potassium fertilization on elephantgrass - Napier cv. were evaluated. An incomplete $\mathrm{N} x \mathrm{~K}$ factorial arrangement was studied in randomized block design with three replications with seven N levels (20, 50, 100, 200, 300, 350 and $380 \mathrm{~kg} / \mathrm{ha}$ ) and seven $\mathrm{K}$ levels $(16,40,80,160,240,280$ and $304 \mathrm{~kg} / \mathrm{ha})$. The fourteen $\mathrm{N}$ and $\mathrm{K}$ combinations were obtained according to the Box Berard Matrix, increased 3, with an extra point. The elephantgrass - Napier cv. mass production increased $86 \%$ in response to $\mathrm{N}$ and $\mathrm{K}$ fertilizers. The leaf/stem ratio and $\mathrm{Mg}^{2+}$ content negatively decreased as $\mathrm{K}$ levels increased. The $\mathrm{P}$ and $\mathrm{Ca}{ }^{2+}$ contents decreased as $\mathrm{N}$ levels increased, while the crude protein content quadraticly increased by the $\mathrm{N}$ and $\mathrm{K}$ fertilization. Potassium content increased with $\mathrm{K}$ fertilizer but decreased as $\mathrm{N}$ fertilizer doses increased. The critical K level was 1.85 dag $/ \mathrm{kg}$ herbage dry matter.
\end{abstract}

Key Words: critical level, crude protein, dry matter, mineral

\section{Introdução}

A formação de pastagens nas regiões tropicais e subtropicais é quase sempre relegada às terras de baixa fertilidade, resultando no desenvolvimento lento das gramíneas. Surge, então, a necessidade de aumentar a produtividade dessas pastagens, o que requer a aplicação de fertilizantes, a fim de permitir exploração animal mais intensiva, capaz de competir com outras formas de exploração dentro da atividade agrícola.

A determinação de níveis críticos e das doses recomendáveis de nutrientes a serem adicionadas ao soloé de vital importância para uso racional de fertilizantes.
Entre os macronutrientes, o nitrogênio e o potássio possuem papel fundamental para a nutrição das plantas; o nitrogênio, por ser constituinte essencial das proteínas e interferir diretamente no processo fotossintético, pela sua participação na molécula de clorofila, e o potássio, por ser o cátion em maior concentração nas plantas, sendo um nutriente com relevantes funções fisiológicas e metabólicas como ativação de enzimas, fotossíntese, translocação de assimilados e também absorção de nitrogênio e síntese protéica, tornando-se, portanto, limitante em sistema de utilização intensiva de solo.

A produção agrícola está diretamente relacionada

\footnotetext{
1 Parte da Tese de Mestrado apresentada pelo primeiro autor à Universidade Federal de Viçosa

2 Aluno do curso de Doutorada em Zootecnia da Universidade Federal de Viçosa.

3 Professor do DZO/UFV - 36571-000 - Viçosa, MG.

4 Professor do DZO/UFV - 36571-000 - Viçosa, MG.

5 Professor do DSO/UFV - 36571-000 - Viçosa, MG.

6 Pesquisador da EMBRAPA/CNPGL - 36038-330 - Juiz de Fora, MG.

7 Bolsista de Iniciação Científica do CNPq.
} 
com a disponibilidade dos nutrientes, que em determinada condição depende, além das formas químicas em que o mesmo se encontra no solo, da capacidade de absorção da cultura, do desenvolvimento do sistema radicular, do tempo de crescimento e, ainda, das condições climáticas e da disponibilidade de outros nutrientes.

O incremento na produção da matéria seca, principalmente em forrageiras com alto potencial de produção, em decorrência da aplicação de nitrogênio, foi relatado por vários autores (CAIELLI et al., 1991; COSTA, 1995; GUERRERO et al., 1970a,b; MONTEIRO e WERNER, 1977; OAKES, 1967; e VICENTE-CHANDLER et al., 1959a, b).

No entanto, é importante conhecer como o nitrogênio contribui para a produção e a qualidade das plantas forrageiras, melhorando assim a sua utilização. Segundo COOKE (1972), os aumentos significativos de produção devem surgir do efeito de interações, entre as quais se incluem o potencial produtivo de animais e a quantidade de forragem oferecida, os níveis de adubação e manejo das pastagens, a quantidade de forragem disponível e a lotação das pastagens, bem como a disponibilidade de outros nutrientes notadamente, o potássio.

O potássio, além de ser um elemento de alto custo de importação, sofre grande lixiviação nos solos altamente intemperizados e profundos e, assim, não se acumula de maneira significativa nos solos (PREZOTTI et al., 1988). É, portanto, um elemento do qual não se esperam, nesses solos, respostas residuais por um período muito longo, devendo sua recomendação de adubação basear-se no conhecimento de seu nível crítico no solo.

O nível crítico de um nutriente, tanto no solo quanto na planta, refere-se à sua concentração abaixo da qual existe alta probabilidade de resposta da produção à sua adição ao solo.

Não basta somente conhecer o nível crítico para determinada cultura. É preciso também conhecer todas as variáveis envolvidas direta ou indiretamente no processo, ou seja, aquelas que influem no valor encontrado, como tipo de solo, teor de argila, tipo de gramínea, extrator usado e outros, para que este possa ser extrapolado para outro tipo de solo (FREIRE et al., 1979; NOVAIS e KAMPRATH, 1979).

A composição mineral de espécies forrageiras varia com uma série de fatores, entre os quais se destacam: solo e adubações realizadas, diferenças genéticas entre espécies, variedades, estações do ano e intervalo de cortes. Neste intento, VICENTECHANDLER et al. (1959b), estudando o efeito da fertilização nitrogenada, a freqüência de corte sobre o rendimento e a composição química de três gramíneas tropicais, observaram que o rendimento e a concentração de lignina aumentaram, enquanto os teores de proteína, fósforo, cálcio, magnésio e potássio diminuíram com o aumento do intervalo de cortes.

Trabalhos de diversos autores evidenciam o grande efeito do nitrogênio no aumento tanto da produção (COSTA, 1995; RIBEIRO, 1995; WOOARD e PRINE, 1991), quanto do teor de proteína das plantas (RIBEIRO, 1995; PACIULLO, 1997). GUERRERO et al. (1970a) também citaram vários trabalhos em que a aplicação de nitrogênio em pastagem de capimelefante, em quase todos os casos, aumenta os rendimentos de forragem, embora a magnitude deste incremento seja variável e dependente tanto do nível de nitrogênio aplicado quanto de outras variáveis ligadas ao solo, disponibilidade de outros nutrientes, assim como as condições climáticas e os intervalos de corte.

$\mathrm{O}$ aumento na produção de forragem, em resposta à adubação nitrogenada, implica também na aplicação de outros elementos, como potássio e fósforo, além da adoção de práticas adequadas de manejo.

GAVILLON e THEREZA QUADROS (1969), estudando as variações do teor de potássio nas forrageiras de pastagens nativas do Rio Grande do Sul, verificaram que estes teores foram sempre suficientes para a nutrição animal (superiores a $0,6 \mathrm{dag} / \mathrm{kg}$ na matéria seca). Porém, ao considerarem as exigências das plantas, constataram que, em várias regiões, as forrageiras apresentaram valores inferiores aos seus requerimentos, mesmo nas espécies menos exigentes (teores abaixo de 1,0 dag/kg na matéria seca), indicando que melhoria nas mesmas deverá ser acompanhada de adubação potássica.

MESA et al. (1988a) acrescentaram que o potássio exerce grande influência no metabolismo, apesar de nem sempre ter efeito marcante sobre os rendimentos de matéria seca, mas é necessário que esteja presente em quantidade adequada, principalmente quando a exploração das pastagens se dá de forma intensiva.

Realizou-se o presente trabalho com os objetivos de avaliar o efeito de diferentes doses de nitrogênio e potássio sobre o rendimento de matéria seca e a composição química do capim-elefante, bem como determinar o nível crítico de potássio no solo e na planta. 


\section{Material e Métodos}

O experimento foi conduzido em uma área do Departamento de Zootecnia da Universidade Federal de Viçosa, Minas Gerais, no período de outubro de 1995 a abril de 1996. As amostras de solo da área experimental apresentaram as seguintes características químicas: $\mathrm{pH}\left(\mathrm{H}_{2} \mathrm{O}\right.$ 1:25), 5,4; P e K (Mehlich-1), 0,6 e $16,4 \mathrm{mg} / \mathrm{dm}^{3}$, respectivamente; $\mathrm{Ca}, \mathrm{Mg}$ e $\mathrm{Al}(\mathrm{KCl}$ $1 \mathrm{~mol} / \mathrm{L}), 1,3 ; 0,3$; e $0,2 \mathrm{cmol}_{\mathrm{c}} / \mathrm{dm}^{3}$, respectivamente; $\mathrm{H}+\mathrm{Al}\left(\mathrm{Ca}(\mathrm{OAc})_{2} 0,5 \mathrm{~mol} / \mathrm{L}\right), 4,6 \mathrm{cmol}_{\mathrm{c}} / \mathrm{dm}^{3}$. O preparo do solo consistiu de uma aração a $20 \mathrm{~cm}$ de profundidade, após a aplicação de 2,6 t/ha de calcário dolomítico (PRNT 100\%), dose para elevar a saturação de bases a 70\%, seguida de gradeação. Decorridos 30 dias após a aplicação do corretivo, parcelas de $4 \times 5 \mathrm{~m}$ foram demarcadas, nas quais foram abertos quatro sulcos espaçados de $1 \mathrm{~m}$, onde foi aplicado o adubo fosfatado (100 kg/ha de $\left.\mathrm{P}_{2} \mathrm{O}_{5}\right)$ e, em seguida, efetuado o plantio (13/12/1995) com a distribuição das mudas de capimelefante cv. Napier, usando-se colmos inteiros dispostos nos sulcos segundo sistema pé com ponta.

O experimento consistiu de um fatorial incompleto de nitrogênio e potássio, avaliados em sete doses cada. As quatorze combinações entre nitrogênio e potássio, sete doses de nitrogênio (20, 50, 100, 200, $300,350,380 \mathrm{~kg} / \mathrm{ha}$ de $\mathrm{N})$ e sete de potássio $(16,40$, $80,160,240,280,304 \mathrm{~kg} / \mathrm{ha}$ de $\mathrm{K}$ ), foram obtidas de acordo com a matriz experimental Box Berard aumentada 3, com o acréscimo de outro tratamento, cujo número é definido pela expressão: $2^{\mathrm{k}}+2 \mathrm{k}+2 \mathrm{k}+1+1$ (Tabela 1), em que ké o número de fatores envolvidos. Neste trabalho, o k foi igual a 2, nitrogênio e potássio, resultando, dessa forma, nas quatorze combinações entre estes elementos. Os tratamentos foram distribuídos em blocos ao acaso com três repetições.

As adubações nitrogenada e potássica foram parceladas em três vezes iguais e aplicadas ao longo dos sulcos. A primeira foi realizada em 09 de fevereiro de 1996, quando as plantas apresentaram $50 \mathrm{~cm}$ de altura, e as seguintes em 05 e 18 de março de 1996, respectivamente.

Utilizaram-se para fornecimento dos nutrientes os produtos comerciais: superfosfato simples, sulfato de amônio e cloreto de potássio, como fontes de fósforo, nitrogênio e potássio, respectivamente.

Aos 78 dias após o plantio, realizou-se um corte de uniformização e 54 dias após, procedeu-se à colheita da parte aérea das plantas. O corte foi efetuado ao nível do solo, eliminando-se a bordadura, constituída das duas linhas laterais e um metro de cada extremidade da parcela, colhendo-se a biomassa da área útil, correspondente a dois metros lineares das duas fileiras centrais.

A forragem colhida foi fracionada em lâmina foliar e colmo, para se estimar a produção de cada um destes componentes da planta e determinar a relação lâmina/ colmo. As respectivas frações foram acondicionadas em sacos de papel, pesadas e submetidas à secagem a $55-65^{\circ} \mathrm{C}$ e moagem para posteriores análises.

Após o corte, retiraram-se seis amostras de solo por parcela, utilizando um trado tipo holandês, distribuídas ao longo das fileiras recém-cortadas, na profundidade de 0 a $20 \mathrm{~cm}$, que deram origem a uma amostra composta por parcela, para análises. Avaliaram-se nessas amostras os teores de potássio disponível pelo extrator Mehlich, segundo metodologia descrita por Bray (1948), modificada por VETTORI (1969), que consiste na relação solo:extrator de 1:10, com tempo de agitação de cinco minutos. Depois da agitação, a suspensão foi deixada em repouso por 16 horas, quando o extrato foi removido por sucção para a determinação do potássio por fotometria de chama.

Equações de regressão foram ajustadas aos dados de produção de matéria seca, digestibilidade, teores de proteína, fósforo, cálcio, e magnésio na planta e os de

Tabela 1 -Combinação entre nitrogênio e potássio referentes aos tratamentos

Table 1 - Nitrogen and potassium combination according to treatments

\begin{tabular}{|c|c|c|c|}
\hline $\begin{array}{l}\text { Tratamento } \\
\text { Treatment }\end{array}$ & $\mathrm{N}$ & $\mathrm{K}$ & $\begin{array}{l}\text { Expressão } \\
\text { Expression }\end{array}$ \\
\hline & \multicolumn{3}{|c|}{-------------- kg/ha ------------ } \\
\hline 1 & 100 & 80 & \\
\hline 2 & 100 & 240 & $2^{\mathrm{k}}$ \\
\hline 3 & 300 & 80 & \\
\hline 4 & 300 & 240 & \\
\hline 5 & 200 & 40 & \\
\hline 6 & 200 & 280 & $2 \mathrm{k}$ \\
\hline 7 & 50 & 160 & \\
\hline 8 & 350 & 160 & \\
\hline 9 & 100 & 16 & \\
\hline 10 & 20 & 80 & $2 \mathrm{k}$ \\
\hline 11 & 300 & 304 & \\
\hline 12 & 380 & 240 & \\
\hline 13 & 200 & 160 & 1 \\
\hline 14 & 20 & 16 & $1^{1}$ \\
\hline
\end{tabular}

1 Tratamento adicional.

1 Additional treatment. 
potássio na planta e no solo, relação lâmina:colmo, em função das doses de nitrogênio e potássio. Também foram estabelecidas equações de regressão entre teores de potássio no tecido vegetal e dose deste elemento. Com a substituição nestas equações da dose recomendável de potássio, estimou-se o nível crítico deste nutriente na parte aérea do capim-elefante.

\section{Resultados e Discussão}

Observou-se efeito marcante do $\mathrm{N}$ e $\mathrm{K}$ sobre a produção de matéria seca (Figura 1), a qual variou de 2549,0 a $4730,7 \mathrm{~kg} / \mathrm{ha}$ de MS, correspondendo a incremento de $85,6 \%$, realçando a importância de ambos os nutrientes sobre o rendimento forrageiro.

A relação lâmina/colmo diminuiu de 0,92 para 0,68 entre a maior e menor dose de $\mathrm{K}$, segundo a equação $\hat{\mathrm{Y}}=0,93-0,000811^{* *} K\left(R^{2}=0,62\right)$. Essa queda na proporção de lâminas resultou de maior acúmulo da fração colmo em plantas adubadas com maiores doses de $\mathrm{K}$, que pode ser amenizada cortando as plantas a intervalos menores, proporcionando maior relação lâmina/colmo e melhor valor nutritivo.

Os teores de fósforo e cálcio na lâmina foliar variaram inversamente com as doses de nitrogênio aplicadas no solo, o que pode ser explicado pelo efeito de diluição, devido ao rápido crescimento da forragem que recebeu a maior quantidade de adubo

$$
\hat{\mathrm{Y}}=2.427,54+2,9849 * * N+3,8452 * * * K\left(R^{2}=0,78\right)
$$

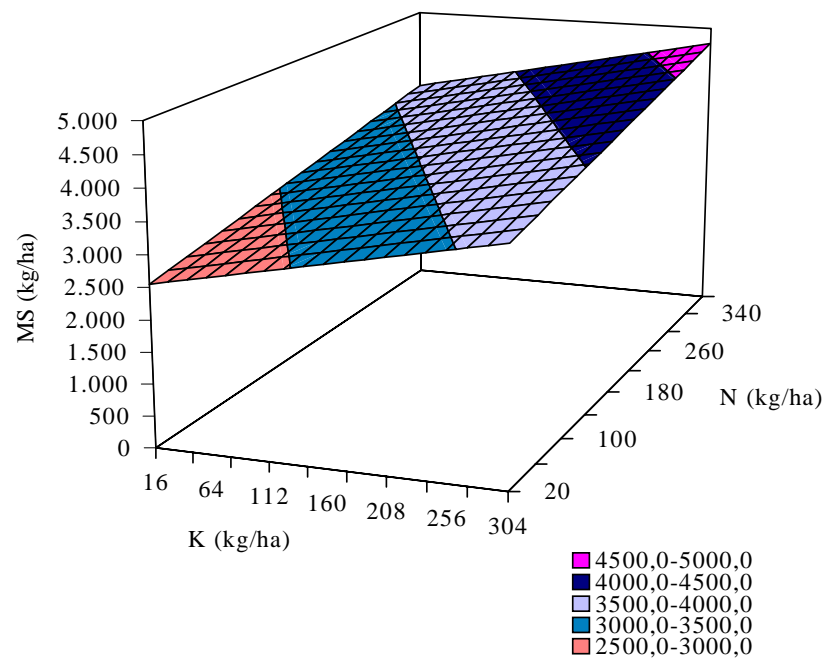

Figura 1 - Produção de matéria seca do capim-elefante, em função das doses de nitrogênio e potássio.

Figure 1 - Dry matter yield of elephant grass, in function of nitrogen and potassium levels. nitrogenado. Todavia, o teor médio de cálcio observado na forragem está dentro do limite considerado como satisfatório para o capim-elefante, segundo SOUZA FILHO (1987), que encontrou valores médios de $0,51 \mathrm{dag} / \mathrm{kg}$ nas lâminas.

Para o magnésio, observou-se decréscimo na fração lâmina foliar de 0,19 para $0,10 \mathrm{dag} / \mathrm{kg}$, entre a menor e maior dose de $\mathrm{K}$, nos teores de magnésio com a adubação potássica (Figura 2).

Essa redução do teor de magnésio decorrente da adubação com K sugere absorção competitiva destes dois elementos, conforme sugerida por MARSCHNER (1995), o qual relatou que cátions como $\mathrm{K}^{+} \mathrm{e} \mathrm{Ca}^{+}$competem efetivamente com $\mathrm{Mg}^{2+} \mathrm{e}$ diminuem grandemente sua absorção, quando potássio e calcário são aplicados.

Os teores de potássio aumentaram com a aplicação do adubo potássico e diminuíram com o nitrogenado (Figura 3).

Aparentemente, a adubação potássica corrigiu o baixo teor deste elemento no solo $\left(16 \mathrm{mg} / \mathrm{dm}^{3}\right)$, o que, juntamente com a grande capacidade desta forrageira em absorver potássio do solo, mesmo em baixas disponibilidades, pode ter contribuído para aumentar seu teor na matéria seca. VICENTE-CHANDLER et al. (1962) consideraram adequada para o crescimento das plantas forrageiras disponibilidade de potássio no solo que proporcione às referidas plantas

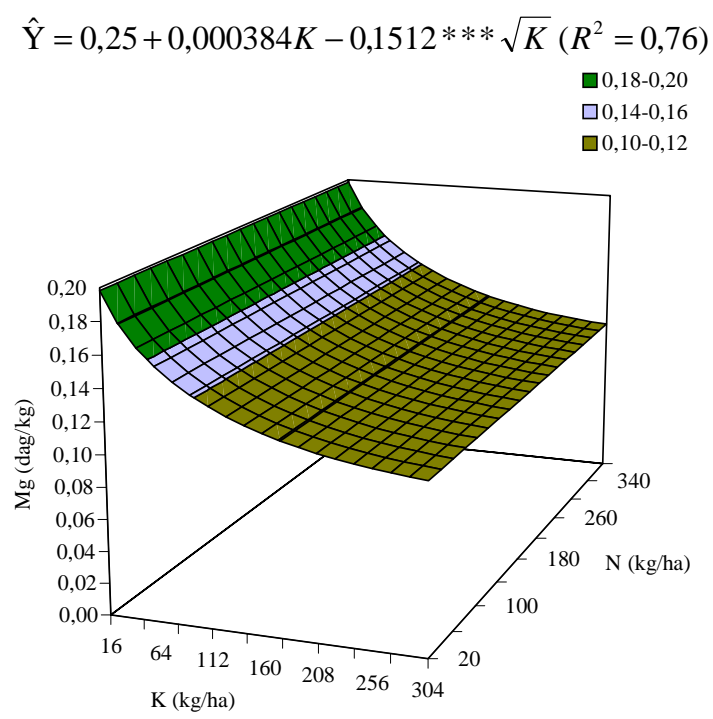

Figura 2 - Teores de magnésio na fração lâmina foliar do capim-elefante, em função das doses de nitrogênio e potássio.

Figure 2 - Contents of magnesium in the leaf blade fraction of elephant grass, in function of the nitrogen and potassium levels. 
Rev. bras. zootec.

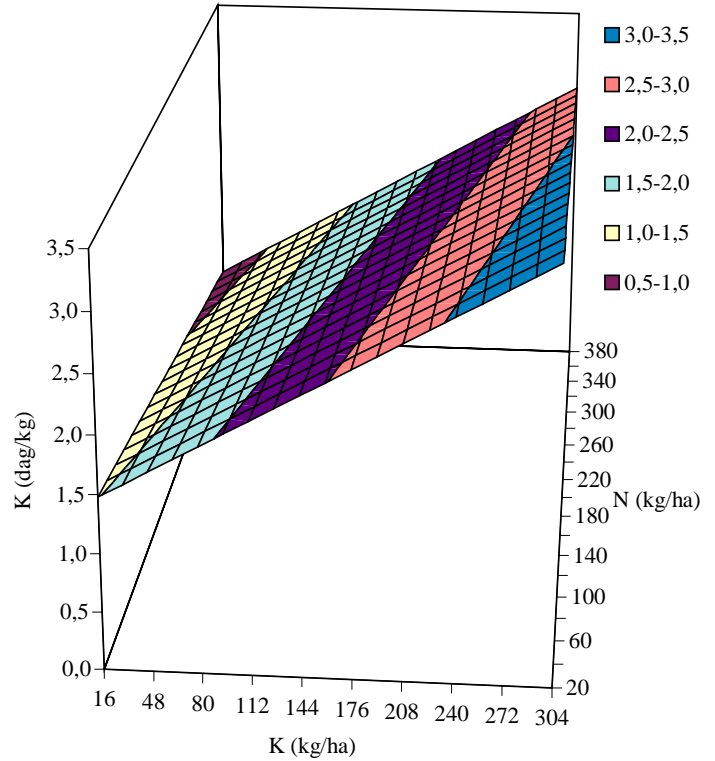

Figura 3 - Teores de potássio na lâmina foliar do capimelefante, em função das doses de nitrogênio e potássio.

Figure 3 - Contents of potassium in the leaf blade of elephant grass, in function of the nitrogen and potassium levels.

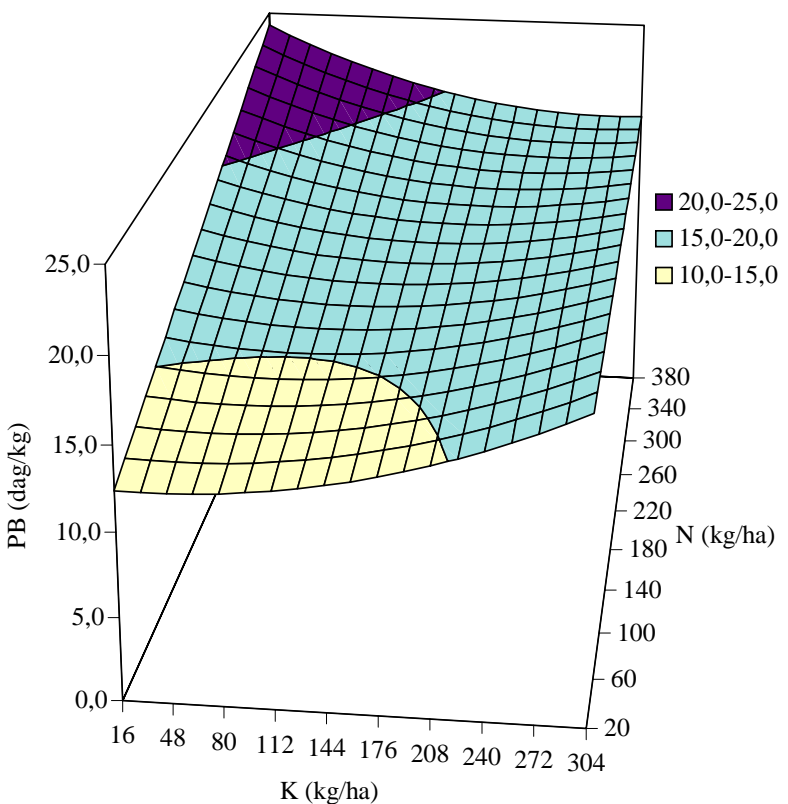

Figura 4 - Teor de proteína bruta na lâmina foliar do capimelefante, em função das doses de nitrogênio e potássio.

Figure 4 - Contents of the crude protein in the leaf blade of elephant grass, in function of nitrogen and potassium levels.

Tabela 2 - Regressão dos teores de potássio nas fraç̃es lâmina foliar, colmo e lâmina foliar+colmo, do capim-elefante, em função das doses de nitrogênio e, ou, potássio e respectivas doses recomendáveis e níveis críticos (NiCri) de potássio

Table 2 - Regression of potassium contents in the leaf blade, stem and leaf blade+stem fractions, of the elephantgrass, in function of nitrogen and, potassium levels and respective recommended levels and critical level (CriLev) of the potassium

\begin{tabular}{|c|c|c|c|}
\hline \multirow[t]{2}{*}{$\begin{array}{l}\text { Equações } \\
\text { Equations }\end{array}$} & \multicolumn{2}{|c|}{$\begin{array}{l}\text { Doses recomendáveis } \\
\text { Recommended levels }\end{array}$} & \multirow{2}{*}{$\begin{array}{c}\text { NiCri } \\
\text { CriLev } \\
\mathrm{K} \\
\end{array}$} \\
\hline & $\mathrm{N}$ & $\mathrm{K}$ & \\
\hline$\overline{\text { Colmo }}$ & \multicolumn{2}{|c|}{----- (kg/ha) ------ } & (dag/kg) \\
\hline Stem & & & \\
\hline$\hat{\mathrm{Y}}=0,90+0,006395^{* * *} \mathrm{~K} \quad\left(\mathrm{R}^{2}=0,56\right)$ & 365,79 & 192,0 & 2,13 \\
\hline \multicolumn{4}{|l|}{$\begin{array}{l}\text { Lâmina foliar } \\
\text { Leaf blade }\end{array}$} \\
\hline$\hat{\mathrm{Y}}=1,41+0,00699 * * * \mathrm{~K}\left(\mathrm{R}^{2}=0,59\right)$ & 365,79 & 192,0 & 2,00 \\
\hline \multicolumn{4}{|l|}{$\begin{array}{l}\text { Lâmina + Colmo } \\
\text { Leaf blade }+ \text { Stem }\end{array}$} \\
\hline$\hat{\mathrm{Y}}=1,57+0,02427 * \mathrm{~N}-0,02371 * \mathrm{~N}+0,006671\left(\mathrm{R}^{2}=0,56\right)$ & 365,79 & 192,0 & 1,85 \\
\hline
\end{tabular}

${ }^{*},{ }^{* *} \mathrm{e}^{* * *}=$ Significativo a 10,5 e $1 \%$, respectivamente.

${ }^{*},{ }^{* *}$ and ${ }^{* * *}=$ Signifcance at 10,5 and $1 \%$, respectively. 
teor de 1,5 a 2,0 dag/kg na matéria seca. De fato, aplicações maciças de adubo potássico devem ser evitadas para prevenir a absorção de luxo e evitar a interferência na absorção de magnésio e cálcio pela planta (GOMIDE, 1986).

A adubação nitrogenada com baixas doses de $\mathrm{K}$ (Figura 4) aumentou os teores de proteína bruta (PB) na MS. Já nos tratamentos em que houve elevada produção de MS (Figura 1), constatou-se redução nos teores de $\mathrm{PB}$, caracterizando-se em um efeito de diluição. Por outro lado, o rendimento de $\mathrm{PB}$ aumentou de 236 para $744 \mathrm{~kg} / \mathrm{ha}$ de $\mathrm{PB}$, resultante de maiores produções de MS.

O nível crítico de potássio na lâmina + colmo de $1,85 \mathrm{dag} / \mathrm{kg}$ (Tabela 2) foi inferior aos obtidos por MESA et al. (1988b) para as cultivares de Pennisetum purpureum Schum: King grass, TA-144, CRA-265 e 801-4, cujos valores foram, respectivamente, 2,41; 2,76; 2,95; e 3,16 dag $/ \mathrm{kg}$, porém está próximo dos 2,0 dag/kg sugerido por WERNER (1986) como teor médio para recomendação de adubação de reposição. Esta variação entre as cultivares e entre estas e a Napier deste estudo pode ser atribuída a fatores genéticos, além de outros como extrator usado, teor e qualidade da argila, idade da planta e metodologias empregadas.

\section{Conclusões}

A adubação potássica e nitrogenada influenciou positivamente a produção de matéria seca.

Os teores de PB aumentaram com a adubação nitrogenada e decresceram com a potássica. O rendimento de PB aumentou linearmente com as doses de nitrogênio e potássio.

Os teores de fósforo e cálcio diminuíram com a adubação nitrogenada e os de magnésio, bem como a relação lâmina/colmo, decresceu com a adubação potássica. Já os teores de potássio aumentaram com a adubação potássica e diminuíram com a adubação nitrogenada.

\section{Referências Bibliográficas}

CAIELLI, E.L., BONILHA NETO, L.M., LOURENÇO, A.J. 1991 Avaliação agronômica e qualitativa de pastos de capim-elefante Napier (Pennisetum purpureum Schum.) fertilizados com nitrogênio ou consorciados com leguminosas tropicais para produção de carne. Bol. Ind. Anim., 48(1):63-76.

COOKE, G.W. 1972. Fertilizing for maximum yield. London: Crosby Lockwod and Son. 575p.

COSTA, N.L. 1995. Adubação nitrogenada e consorciação de capim-elefante (Pennisetum purpureum cv. Cameroon) com leguminosas forrageiras tropicais. Pesq. Agropec. Bras., 30 (3):401-408.

FREIRE, F.M., NOVAIS, R.F., BRAGA, J.M. et al. 1979. Adubação fosfatada para cultura da soja (Glicine max (L) Merrill) baseada no fósforo "disponível" em diferentes extratores químicos e no "fator capacidade". R. Bras. Ci. Solo, 3(2):105-111.

GAVILLON, O., THEREZA QUADROS, A. 1969. Variação no teor de potássio nas pastagens nativas do Rio Grande do Sul. Rio Grande do Sul: Rep. Prod. Animal da S.A. do Rio Grande do Sul. p.35 (Boletim técnico, 14).

GOMIDE, J.A. 1986. Adubação fosfatada e potássica de plantas forrageiras. In: PEIXOTO, A.M., MOURA, J.C., FARIA, V.P. (Eds.). Pastagens: fundamentos da exploração racional. Piracicaba: FEALQ. p.155-64.

GUERRERO, R., FASSBENDER, H.W., BLYDENSTEIN, J. 1970a. Fertilización del pasto elefante (Pennisetum purpureum) en Turrialba, Costa Rica. I. Efecto de dosis crecientes de nitrógeno. Turrialba, 29(1):53-57.

GUERRERO, R., FASSBENDER, H.W., BLYDENSTEIN, J. 1970b. Fertilización del pasto elefante (Pennisetum purpureum) en Turrialba, Costa Rica. II. Efecto de combinaciones nitrógenofósforo. Turrialba, 20(1):59-63.

MARSCHNER, H. 1995. Mineral nutrition of higher plants. 2.ed. London: Academia. 889p.

MESA, A.R., HERNÁNDEZ, M., REYES, F. et al. 1988a Determinacion de los niveles criticos de N, P y K, rendimiento de materia seca y composicion quimica en Andropogon gayanus cv. CIAT-621. Pastos y Forrage, 11(3):235- 41.

MESA, A.R., MENDOZA, F., AVILA, V. 1988b. Niveles criticos de $\mathrm{K}$ en Pennisetum purpureum, Schum. Pastos y Forrages, 11 (1):68-72.

MONTEIRO, F.A., WERNER, J.C. 1977. Efeitos das adubações nitrogenada e fosfatada em capim-colonião, na formação e em pasto estabelecido. Bol. Ind. Anim., 34(1):91-101.

NOVAIS, R.F., KAMPRATH, E.J. 1979. Parâmetros das isotermas de adubação de fósforo como critério de recomendação de adubação fosfatada. R. Bras. Ci. Solo, 3(1):37-41.

OAKES, A.J. 1967. Effect of nitrogen fertilization and plant spacing on yield and composition of Napier grass in the dry tropics. Trop. Agric., 44(1):77-82.

PACIULLO, S.C.P. Produtividade e valor nutritivo do capimelefante "Anão" (Pennisetum purpureum Schum cv. Mott) ao atingir 80 e $120 \mathrm{~cm}$ de altura sob diferentes doses de nitrogênio. Viçosa, MG: UFV, 1995. 60p. Tese (Mestrado em Zootecnia) - Universidade Federal de Viçosa, 1997.

PREZOTTI, L.C., DEFELIPO, B.V., ALVARES V., V.H. et al. 1988. Nível crítico de potássio no solo para a produção de mudas de eucalipto. R. Bras. Ci. Solo, 12(1):65-70.

RIBEIRO, K.G. Rendimento forrageiro e valor nutritivo do capimelefante "Anão", sob cinco doses de nitrogênio ao atingir 80 e 120 cm de altura. Viçosa, MG: UFV, 1995.60p. Dissertação (Mestrado em Zootecnia) - Universidade Federal de Viçosa, 1995.

SOUZA FILHO, A.P.S. Rendimento forrageiro, composição química e digestibilidade das frações folha e colmo do capim-elefante (Pennisetum purpureum Schum.) Dwarf em diferentes idades. Lavras, MG: ESAL, 1987. 104p. Disertação (Mestrado em Zootecnia) - Escola Superior de Agricultura de Lavras, 1987.

VETTORI, L. 1969. Métodos de análise de solo. Rio de Janeiro: Ministério da Agricultura, EPF, 24p. (Boletim técnico, 7). VICENTE-CHANDLER, J., PEARSON, R.W., ABRUNA, F. et 
Rev. bras. zootec.

al. 1962. Potassium fertilization of intensively managed tropical grasses under humid tropical conditions. Agron. J., 54(5):450-3.

VICENTE-CHANDLER, J., SILVA, S., FIGARELLA, J. 1959a. Effects of nitrogen fertilization and frequency of cutting on the yield and composition of Napier grass in Puerto Rico. J. Agric. Univ. Puerto Rico, 43(4):215-27.

VICENTE-CHANDLER, J., SILVA, S., FIGARELLA, J. 1959b. The effect of nitrogen fertilization and frequency of cutting on the yield and composition of three tropical grasses. Agron. J., 51(3):202-6.
WERNER, J.C. 1986. Adubação de pastagens. 2.ed. Nova Odessa: Instituto de Zootecnia, 49p.

WOODARD, K.R., PRINE, G.M. Forage yield and nutritive value of elephantgrass as affected by harvest frequency ad genotype. Agron. J., 83(3):541-6.

Recebido em: 23/02/99

Aceito em: 02/05/00 